\title{
Halloween and the Limits of Cinematic Meaning ${ }^{1}$
}

\author{
György Kalmár \\ University of Debrecen (Hungary) \\ E-mail: gykalmar@yahoo.com
}

\begin{abstract}
The article reads John Carpenter's Halloween (1978) from the perspective of the (im)possibilities of cinematic meaning. The horror film seems to be an especially fruitful field for such studies, since its aestheticpsychological mechanism usually aims at destroying the kind of spectatorial position necessary, at least according to semiotic and postsemiotic theory, for the generation and reading of meaningful signs. Placing the film in the theoretical context of such scholars as Roland Barthes, Jacques Lacan, Kaja Silverman, Steven Shaviro and Todd McGowan, I attempt to analyse the ways the film disables the production of semiotic meaning and rewrites some of the well-established concepts of film theory. I call into play Barthes's concept of the punctum, McGowan's cinema of intersection, Lacan's later theory of the sinthome, Silverman's post-Lacanian ideas about the cinematic gaze and the spaces of spectatorship, and Shaviro's provocative insights about affective cinema so as to indicate how a film may prove its quality precisely at the points where it does not make sense.
\end{abstract}

Keywords: horror films, the cinematic gaze, meaning in semiotic and postsemiotic theory, Barthes, Lacan.

After many years of watching and teaching horror films, I still consider one of the most powerful images of the genre the picture of Michael Myers (Nick Castle) standing motionlessly, staring straight at Laurie (Jamie Lee Curtis), at the camera, and the spectator in John Carpenter's Halloween (1978). This image may define the thrills of horror film spectatorship to a large extent, and can also serve as a perfect example of what Roland Barthes calls the punctum. In a now famous part of Camera Lucida, discussing photography, Barthes makes a distinction between two elements of photographic meaning. On the one hand there is studium, "a kind of general, enthusiastic commitment" to photographs

1 The research for this article was supported by the TÁMOP 4.2.1./B-09/1/KONV2010-0007 project. The project is implemented through the New Hungary Development Plan, co-financed by the European Social Fund and the European Regional Development Fund. 
(1981, 26), a familiar way of looking at the object "as a consequence of my knowledge, my culture" that refers to "a classical body of information" (1981, 25-26); and on the other hand, there is punctum, the description of which though apparently unintended by Barthes - says as much about horror as about the limits of symbolic meaning: "The second element will break (or punctuate) the studium. This time it is not I who seek it out (as I invest the field of studium with my sovereign consciousness), it is this element which rises from the scene, shoots out of it like an arrow, and pierces me. A Latin word exists to designate this wound, this prick, this mark made by a pointed instrument [...]. This second element which will disturb the studium I shall therefore call punctum; for punctum is also: sting, speck, cut, little hole-and also a cast of the dice. A photograph's punctum is that accident which pricks me (but also bruises me, is poignant to me)" (1981, 26-27).

Barthes's punctum describes my relation to the figure of Myers: it is a strong image that strikes me, pricks me, maybe the richest in meaning, yet this meaning is impossible to articulate through words. The lurking and gazing image of Myers in Halloween reminds me of the power of images to subjugate the subject, and of the limits of articulated, symbolic meaning: when I look at this figure looking at me there seems to be a short-circuit in the act of looking in which my distance from the image threatens to collapse. The image does to me what the killer Myers does to its victims: it actively haunts me, pierces me, disrupting my relation to symbolic and narrative meaning. I know very well that this is a crucial image, one that I should make sense of and interpret (so as to regain mastery over the visual field, for example), yet when I gaze back there is only a strange silence and the waves of affective bodily responses. [Fig. 1.]

Film theory, even at its most realist trends, is deeply embedded in a kind of idealism that supposes that images make sense, that visual impressions can be (and must be) reintegrated into structures of meaning. As Steven Shaviro argues: "Indeed, the fear and disgust of images is traditional in Western thought. [...] Metaphysics prefers the verbal to the visual, the intelligible to the sensible, the text to the picture, and the rigorous articulations of signification to the ambiguities of untutored perception" $(1993,15)$. From the beginnings of European thought, from Platonic idealism to semiotics, post-semiotics, constructivism, and maybe even "classical" Lacanian film theory the ideas that bodies signify human beings, the visible finds its meaning in a non-visible totality, and images can (and must) be explained have been most influential. As Hans Belting remarks apropos of early Christianity's struggle to "control images with words," "theologians were satisfied only when they could 'explain' the images" $(1994,1)$. Obviously, this compulsive strive to explain, to know, to grasp, to reintegrate into the field of language, is an act of regulative power that 
misses the point (the punctum) of the image, for, as Shaviro rightly remarks (in one of his unintentionally psychoanalytical moments), "what is most important is what we are unable to acknowledge" $(1993,10)$.

In his informative chapter on Halloween in Going to Pieces, Adam Rockoff stumbles across the problem of meaning and meaninglessness in the film. Taking a kind of careful middle ground, he counters psychoanalytical interpretations (like that of Robin Wood) that attempt to write a case study of sexual repression behind the mask of the killer, arguing that the film is "not psychologically complex" (2002, 55) and "it is extremely difficult to try and force the film into any psychosexual context" $(2002,65)$. Though for Rockoff the term "meaningless" sounds like a demeaning accusation, something the film has to be protected from $(2002,56)$, he does offer an alternative to the "overanalysis of the film" $(2002,56)$ that is close to my point here. About the possible motivations and meaning of the killer's violent behaviour, he bluntly states: "Why does Michael kill? Because like the shark in Jaws (1975), that's simply what he does" $(2002,56)$. I think this is precisely the point: that there is no meaning behind that mask of Myers, no psychotic subject with a case history; what makes the film memorable (a punctum) is not psychological depth of character, but, on the contrary, its flatness, visual/cinematic characteristics that can be analyzed but cannot be translated into conceptual language. The point is the punctum: the places where it does not make sense.

I would argue that whether films represent (á la semiotics) and/or affect (á la Shaviro) does not depend so much on the generalizing declarations of film theorists, but much rather on the specific "film language" of the particular piece. Obviously, all films represent and affect, make sense and deny sense, though in different ways. I find horror film special in its relation to meaning, and I find Halloween especially outstanding for its brilliant techniques of collapsing distance, denying depth, and destroying spectatorial control over the image. In what follows, my aim is to analyse the techniques through which Halloween accomplishes this, in a loose but ever-present theoretical framework indicating why this meaninglessness may be significant.

\section{Horror and the Cinema of Intersection}

In his recent book, The Real Gaze (2007), Todd McGowan comes up with a classification of cinema that can be productively applied to the study of horror films. McGowan himself is not interested in horror: his aim is to establish a new kind of psychoanalytical film theory that can break away from its early forms established in the 1970's on basis of Lacan's article on the mirror stage and 
Althusser's theory of the interpellation of the subject by ideology. On basis of how films relate to the impossible (Real) object, he distinguishes between the cinema of fantasy, desire, integration (of desire and fantasy), and (their) intersection. It is when he comes to the description of the cinema of intersection that the book becomes a useful tool for a reformulation of some of the theoretical issues of horror film.

Whereas the cinema of integration (the most typical example of which is mainstream Hollywood cinema) combines the worlds of desire (a world of lack) and fantasy (its imaginary fulfilment), thus putting an empirical object in the position of the impossible object of desire, and creating a narrative that leads to the attainment of this object, the cinema of intersection shows these worlds as distinct, separated, and only intersecting: "Hollywood's escapist films, for the most part, belong to the cinema of integration rather than the cinema of intersection because they transform the impossible object into an ordinary object. [...] When the impossible object becomes an empirical object, one can experience it integrated within the field of vision without a disruption of that field. In the cinema of intersection, however, the encounter with the impossible object completely shatters the field of vision. The gaze and the field of vision cannot simply coexist: the emergence of one implies the shattering of the other." (McGowan 2007, 165.)

The most thought-provoking part in McGowan's theory of the cinema of intersection is calling attention to those points where (just like in case of Barthes's punctum) the order of meaning collapses, and cinema fails to fulfil its "ideological function" that "consists in providing a fantasmatic image of the successful sexual relationship" $(2007,203)$. "Hence, when we experience this failure, we grasp the hole that exists within the symbolic order. On the one hand, this traumatizes the subject, depriving the subject of the idea of ever escaping lack, but on the other hand, it frees the subject to enjoy in the real" (2007, 203-204).

McGowan's "cinema of intersection" is a useful conceptual tool for horror film studies because it describes the traumatic collision of two worlds that does not lead either to narrative closure or to the possibility of a seamless, totalizing interpretation. What he calls the world of desire (and lack) obviously corresponds to the "normal," everyday world of the small American town in Halloween. However, instead of the usual fantasy of the promise of the successful sexual relationship and the usual barriers between the subject and the object that the subject has to overcome through the narrative (thus attaining an integration of subject and object, desire and fantasy), we have something horribly different. The object taking the position of the impossible object of desire is not beautiful but horrible, and instead of waiting behind barriers for 
the subject to fight one's way through for it, it "rises from the scene" (Barthes 1981, 126), actively comes for the subject, transgressing all borders. This horrible object does not integrate into or communicate with the normal (symbolic) order, it intersects it, shatters it, pointing out its limits and artificiality. The subject of this kind of cinema (both protagonist and spectator) lose all mastery over the visual field, become passive, paranoid, shocked, persecuted, abjected by this meaningless image and the powerful conceptual and sensual shocks that this intersection brings about.

When Michael Myers appears in Haddonfield, his figure (referred to simply as "The Shape" in the end credits) intersects the "normal" world of meaning. Around him we see no ordinary people, only empty streets, dark houses, and dead leaves. He is the killer that cannot be killed, and (maybe even more importantly) the seer-voyeur-onlooker who cannot be looked in the eyes. The black holes of his mask become the abysses in which the visual field loses its structure and meaning. According to Kaja Silverman (who builds on Jean-Paul Sartre's analysis of voyeurism and subjectivity in Being and Nothingness), to be a subject means to be looked at, to exist for an Other. In Sartre's example (taken up by Lacan and Silverman as well) the moment when the voyeur at the keyhole (who imagines to be the master of the situation) realizes that he may as well be seen, an object in another's eyes, he loses his (imaginary) mastery: "The voyeur's apprehension of his own specularity also leads to the discovery that he has his 'foundations' outside himself, and that he exists for the Other" (Silverman 1996, 165). The voyeuristic Other, who keeps looking at us without blinking and shame, who does not get embarrassed when we look back (the white mask never blushes) is not a subject (like the spectator or Laurie). He is an Other lacking subjectivity, he is a mask, an empty gaze, a knife, he intersects and pierces not only bodies, but also the field of vision. The black holes of his eyes displace the focus point of monocular perspective, the transcendental focal-point of cinematic meaning that serves as the guarantee of signification and idealization. His gaze simultaneously deprives the subject of all mastery and shatters the structures of the visual field.

According to "classical" Lacanian theory, the encounter with the Real (the ultimate, impossible object) can be either one of extreme enjoyment (Jouissance) or traumatic. Both cases, however, entail a (momentary) loss of subjectivity. As opposed to romantic films, horror (as most films of David Lynch, McGowan's favourite example), depict this encounter and the loss of subjectivity as threatening, damaging, and traumatic. Nevertheless, even if the narrative and the fantasy that fills the place of the Real are different, the similarities between romantic films and horror are as apparent as uncanny: both put on stage the encounter with the impossible object, and both articulate the 
fulfilment of this encounter through bodily interaction (a kiss in the sunset or sex in one, and the monster eating the subject or the subject killing the monster in the other). Thus, I would argue that horror film can be read as an uncanny double of romantic film, where the impossible object of desire is replaced by the "monster," sex is replaced by murder, and the phantasmatic integration of desire and the ultimate object is replaced by the shattering intersection of the Symbolic and the Real. This proximity between romance and horror may also have disorienting effects. As Rick Worland rightly notes, "part of Halloween's disturbing charge comes from the ways Michael is constructed as Laurie's fantasy lover" $(2007,235)$.

The affair of the protagonist and the monster can be read as the story of a hysterical symptom: it is a substitute satisfaction, something replacing the (nonexistent) successful sexual relationship, something that brings as much pain as joy, but still a relationship to enjoyment that works. In horror films the Real intersects with the Symbolic, and the subject - no matter whether protagonist or spectator - is intersected by an otherness that is beyond the reach of meaning. When the knife slashes the skin, dissecting the unified body, which serves as the fundamental ground of ideology and coherence, we are looking at this meaningless intersection. Just as the shades of the venetian blinds cut Laurie's face into pieces, we are intersected, cut up, disembowelled by what we see. Together with the shape of our well-structured subjectivity, it is our relation to meaning that is threatened. [Fig. 2.]

\section{The Symptom that does not Speak}

Laurie, the "final girl" of Halloween (so as to use Carol Clover's term) does not have a boyfriend. She establishes the prototype of a whole set of teenage girls in the genre who never have sex, but survive the slasher film while all their sexually active friends get slashed, stabbed, and sliced up. It was Carol Clover who rescued the genre from the conventional dismissal as a simple misogynistic fantasy, and established in critical discourse the theory of "crossgender identification" $(2002,80)$, "the fluidity of engaged perspective" (2002, 80 ), "masochistic pleasures" of spectatorship $(2002,81)$, and the uncanny link between the killer and the Final Girl $(2002,81)$. Clover systematically undermines the rigid binary system of gendered oppositions (active/passive, male/female, sadistic/masochistic, killer/victim) that characterized both former slasher-criticism and 1970's Lacanian film theory. She argues that the "fluidity of engaged perspective is in keeping with the universal claims of the psychoanalytic model: the threat function and the victim function coexist in the 
same unconscious, regardless of anatomical sex" $(2002,80)$. In other words, the separation of male and female roles, and sadistic and masochistic pleasures are artificial and untenable ones: the subject of horror cinema is open to both positions and pleasures, "shifts back and forth with ease" $(2002,85)$. "When, in the final scene, she [the Final Girl] stops screaming, looks at the killer, and reaches for the knife (sledge hammer, scalpel, gun, machete, hanger, knitting needle, chainsaw), she addresses the killer on his own terms" $(2002,80)$. Taking Clover's argument one step further, I would argue that the shifting between these positions and the final girl's final move of taking over the killer's attributes (together with his phallic weapon) can also be interpreted as signs of their secret, unconscious connection: in the final scene the final girl becomes the killer, revealing that they have always been connected, have always been each other's symptomatic doubles. [Fig. 3.]

In the film, this is the moment of Laurie's "coming out." Having taken up the killer's knife and stabbing him, she comes out of the closet where she tried to hide. The scene of this "coming out" is lit from the right side, producing strong shadows on the white closet door on the left from where she appears. Her slow coming out is reminiscent of some of the earliest horror films: the lights evoke German expressionist cinema, the way she appears (slowly, first the knife and the hand) clearly evokes the emergence of the monster from the experimental cabin in Edison's 1910 Frankenstein, while the shadow of Laurie's stooped body on the white wall (when she is standing over the supposedly dead body of Myers with the knife in her hand) may remind one of the famous shadow of the vampire in Murnau's Nosferatu (1922). These intertextual references clearly posit Laurie as an emerging monster, and the "threesome" of Myers, Laurie and her shadow (with the shiny knife intersecting the visual field between the three of them) produces an inextricable knot.

So Laurie does not have a boyfriend like her friends, she has no "normal" access to enjoyment. But one day a tall, dark stranger appears in town, a man without a face, in whom (as it is established in the famous first scene) sexuality and killing are connected. He stalks her, appears and disappears, initiating a game of paranoid hide and seek, he often remains invisible to others, creating the "sense of subjective delusion" (Worland 2007, 238). Their connection seems inevitable, we never ask "Why her?", they belong to each other, like to-be-lovers in a romantic film, their relationship is at the centre of the narrative. Diegetically, according to the literal logic of the story, she is his symptom, but figuratively he can be read as hers. He is a symptom that intersects with the social order, does not integrate, only cuts up, shatters, and destroys. As a symptom, Myers is the manifestation of Laurie's unconscious desires, bringing traumatic enjoyment. Visually, this relationship is represented in two ways: 
sometimes we see Laurie catching sight of the stranger for a moment through blinds, windows, in the distance, or otherwise separated from her; and (later in the film) we see the man sharing the same spaces as her, but at a part of that space that she cannot visually control. It is from here that he steps forward (to use Barthes's metaphor) to wound and slash. [Fig. 4.]

The price of this perverse enjoyment embodied by the symptom is exclusion from the field of social-symbolic meaning. Therefore, the narrative must be one of curing, an attempt at understanding the symptom and healing it. In most horror films this "cure" equals to the understanding and killing of the monster/killer. Both steps are crucial: both Freud and the early Lacan regard the symptom as an unconscious message that needs deciphering first in order to be cured. Similarly, the monster must be understood, its secret revealed so as to be killed. The typical monster of horror films raises not only the questions "Does it really exist?", "What is it?", but also the question the subject asks about the big Other: "What does it want (from me)?" Halloween also has the double narrative that usually accompanies this logic in the horror genre: we have one plot-line about the monster/killer going its way, killing victim after victim, getting closer and closer to the protagonist, and we have another narrative (here the adventures of Dr. Loomis) which is about the investigation that aims at revealing the existence and the secret of the monster. The two plot lines go parallel and are intercut: the successful narrative resolution involves the detective (who is often the persecuted protagonist) finding out the secret of the monster, thus being able to kill it before it could kill him/her.

In other words, the typical narrative of horror film can be well described as the appearance of a disturbing, meaningless symptom that brings about traumatic enjoyment, its process of gradual deciphering, and final elimination. This process can also be read as a drama of meaning, as the shattering appearance of a piece of the Real, its going through a process of resignification, and its reintegration into the order that it initially disrupted. This is a nice and neat interpretation of horror cinema, maybe a little bit too nice and neat. There are basically two problems with it. First, Halloween, as many other horror films (following its footsteps), offers no true narrative closure (Myers's supposedly dead body disappears), suggesting that the monster/killer is not dead and the symptom is not cured at all. Secondly, the doctor's (psychoanalyst's?) investigation is based exclusively on his own subjective observations: Myers does not speak. He is a symptom that does not communicate, thus he stays outside the field of symbolic meaning and forecloses the possibility of symbolic mediation and successful reintegration. It may be important to remember the way Norman Bates's behaviour is explained in the last scene of Hitchcock's Psycho (that Halloween alludes to many times) by the psychiatrist. As Rick 
Worland rightly remarks, in Halloween we find no such explanation (2007, 232), which, I would argue, is an important part of its strategy to "break new ground" (Worland 2007, 233), to keep its status as punctum, something that wounds through shattering its relation to the systems of symbolic meaning. Myers stays strictly in the field of vision (that his figure disrupts): Dr. Loomis says he saw pure evil in those darkest of eyes, and the only thing the spectator gets to know about him is the first (primal) scene of the film (shot from his point of view, through a mask) in which he kills his sister after she had sex with her boyfriend. [Fig. 5.]

In her article Hysteria and Sinthome Marie-Hélène Brousse notes that as opposed to dreams that involve language, a "mute vision" or "visual hallucination" (of the patient) without speech or any kind of interaction between the dreamer and the figure of the dream involves processes "outside the possibilities of symbolization by the subject, outside speech, and with no mediation being directly inscribed on his body" (Brousse 2007, 89-90). Myers's silence, his motionless gaze, his masked face (that rejects any form of subjectivity), and his emotionless, almost mechanical killings establish him as such a "mute vision" beyond the reach of meaning, symbolization, or resignification. He is a body without a subject, a body that affects the spectator without making sense. His figure is a point where the film connects with the meaningless: in the Lacanian sense he is a part of the Real that resists integration into the Symbolic, and the element of cinema that marks the limits of verbalization, symbolization, and analysis.

The resistance to symbolic meaning of such images as the gazing Myers comes very close to the late Lacan's concept of sinthome. As Brousse observes, the symptom for the late Lacan is less and less a relationship between the Imaginary and the Symbolic, and more and more one between the Real and the Symbolic $(2007,86)$. The symptom, spelled as sinthome in the crucial 19751976 seminar of the same title, is not so much a metaphor or message to be deciphered, but rather a special relation to enjoyment, a modus operandi for the subject in crisis, an extra ring added to the Borromean knot (made of the three rings of Imaginary, Symbolic, and Real) when the knot does not hold properly. The later Lacan, maybe as a result of an unacknowledged influence of Derrida, regards the symptom and the subject more and more like each other's necessary supplements. Reading the late seminars of R.S. I. and Le sinthome gives one the impression that there is no "normal" subject, that the subject is always already involved in a relationship with the symptom that simultaneously threatens the subject and keeps it together. In other words, the subject of the late Lacan looks very similar to Laurie and the typical horror protagonist, whose organization as a subject involves a part (the symptom) that brings such (obscene) joys and 
sufferings that nobody understands (including the subject oneself). At the place of the functional centre of the ("Oedipalized") subject we find non-meaning and a radical, intimate alterity.

\section{Another Kind of Oedipal Narrative}

From this point of view, the horror film pictures Oedipalization not as a normalization of subjectivity that limits possible subject-positions (as Deleuze and Guattari argue), but as the process through which the subject loses balance, becomes forever complicated and in need of obscene supplements. This does not simply turn the subject into a being cut off from the Real, who therefore keeps producing meaning infinitely (in order to fill the lack of the Real), but also turns the subject into someone who necessarily relies on economies of obscene enjoyment that resist symbolization. The subject, like photographic meaning, is punctuated and organized around points that resist symbolic articulation. Horror film is an exceptional genre because it puts on stage this impossible relationship between the subject and its horrible other in whom one has to recognize the subject's necessary, insurmountable obscene supplement.

Therefore, horror films like Halloween write another (not necessarily Freudian) story of the Oedipal subject, in which the relation to enjoyment shatters one's subjection to what Lacan calls the Law of the Father. In a way, Halloween does stage an Oedipal drama (though not necessarily in the psychoanalytical sense): we have a problem that turns out to be symptomatic (the plague in King Oedipus, the figure of Myers in the film), we have a protagonist who must take on the responsibility to solve the mystery that causes suffering (Oedipus himself in Sophocles and Laurie in the film), and we have a process of events that leads to a traumatic encounter between the subject and its obscene supplement. In Sophocles's King Oedipus it turns out that Oedipus himself is the monster responsible for the plague, but horror films also play with the intimate, supplement-like relationship between the protagonist and his/her persecutor. Both King Oedipus and Halloween lead to a point (of punctum) where subjectivity is smashed together with socially constructive ideologies and fantasies of seamless, meaningful integration. Both Oedipus and Laurie attack the eyes of the monster (and both do that with objects associated with femininity): Oedipus blinds himself with her dead mother's belt buckle, while Laurie stabs Myers with a knitting needle in the neck, a straightened hanger in the eye, and finally with Myers's knife in the chest). Nevertheless, what really wounds the world of meaning, what really makes these scenes punctums is probably the feeling of the world's utter meaninglessness and unfairness, the collapse of our 
belief in an inner sense behind the events. Oedipus, who wanted only the best for all, turns out to be a monster, an outcast, an abject; and in Halloween, after all the deadly stabs and shots, it turns out that the virgin could not kill the monster, the body of evil, nonsensical enjoyment is still alive.

Investigation and the deciphering of the symptom do not lead to truth, meaning, or narrative closure. They lead to a point of punctum where subjectivity disappears in the abyss of an unexplainable obscene enjoyment. The narrative aiming at mastery and knowledge arrives at subjugation and loss: instead of providing control or a graspable meaning, Halloween shows the potential of film to "marginalize consciousness" (McGowan 2007, 13).

In this sense, horror film can be read as a complementary paragraph at the end of Freud's late paper "Analysis Terminable and Interminable," a supplement that suggests that interpretation or analysis may never come to a satisfactory end, that the empire of signs is limited, that it can always happen that things just do not make sense, and idealism (which holds that at the end of the day things have to make sense) is a fantasy. At the end of the day (at least at the end of October 31, 1978), bodies, symptoms, images do not come together in a sublime totality of meaning.

The above mentioned relationship between the Final Girl and the killer is repeated by the relationship of the spectator and the horror film. Halloween directly puts on scene the act of spectatorship: the movie that Carpenter called "a point-of-view film" (Rockoff 2002, 59) is full of instances of looking (Laurie looking at Myers, Myers looking at Laurie and others) framed by windows and doors, which serve as metaphorical screens. (One memorable instance of becoming a spectacle is when Laurie's brunette friend gets stuck in a window in a shirt and panties at the time when Myers is around and watching.) It is also significant that basically everybody watches horror films in the film on Halloween night, mostly in trance-like fascination. I would argue that these framings of the characters, and the acts of looking that are so consciously and self-referentially displayed again and again make the film (also) a study on horror film spectatorship. [Figs. 6-7.]

One of the recurrent motifs of these acts of looking is the subject's lack of mastery over the field of vision, which, in the film, is equal to the subject's ignorance of what is happening. Take a typical example: a girl is changing clothes behind the window panes of the garden door. A dark, shadowy figure appears in the front right corner of the frame, watching her. We understand that our gaze has been his gaze. He makes a noise, the girl looks out, she sees nobody. In a few minutes she is killed. Or another example: Dr. Loomis is hiding in the bushes near the Myers house at night, waiting for Michael to come back. Some kids stop by the house, daring each other to enter the spooky place. 
Loomis makes threatening noises from the bush, the kids run away in panic. Loomis looks happy and satisfied: he thinks he sees and knows what is going on. At that very moment a hand appears behind his shoulders, and touches him. Our characters (almost) never see things from where they think they do, and the point-of-view shots that the film operates with extend that feeling of epistemological uncertainty to the spectator as well. We can never put things into the right perspective.

In The Threshold of the Visible World, a cornerstone in the 1990's psychoanalytic film theory, Kaja Silverman writes: "It has long been one of the governing assumptions of film theory that the cinema derives in some ultimate sense from the Renaissance [...] and that its visual field is defined to a significant degree by the rules and ideology of monocular perspective" (Silverman 1996, 125). Most of the major figures of classical psychoanalytical film theory (such as Christian Metz, Jean-Louis Baudry, or Stephen Heath) agree that in this economy of monocular perspective "the camera designates the point from which the spectacle is rendered intelligible" (Silverman 1996, 125), and it is this superhuman point of imaginary mastery outside the field of vision that the spectator assumes (through suture, and identification with the camera's view), thus attaining meaning and mastery of the filmic image (Silverman 1996, 125-126). Halloween never uses shots that could serve with this kind of mastery of perspective: its point-of-view shots connect the spectator either with a stalking psychotic killer, or with characters who do not have the slightest idea of their approaching gory destiny. Myers's figure works quite similarly to the anamorphic skull in Hans Holbein's The Ambassadors (analysed by both Lacan in Seminar XI and Silverman), as an intersecting, radical otherness, a figure of the meaninglessness of everything else depicted, a figure that shows the futility of our illusions of mastery. Halloween denies us the distance needed for perspective and the kind of totalized meaning associated with it. We are captured, fascinated, subdued by the film, numbed by anxiety, and a feeling of approaching horror gradually takes the place of (our illusion of) clear knowledge and epistemological mastery.

The above mentioned instances of looking that undo the fantasies of transcendence of vision play an essential role in turning the film into an experience of emotionally overloaded non-meaning. Its self-referentiality implies that the spectator may be just another position in these repeated acts of looking and that this position may be very similar to that of Laurie. This mirroring would suggest that when I am watching a horror film I am looking at my own obscene symptomatic supplement, the same way as Laurie does when looking at the killer. We are both disturbed, fascinated and excited, and our bodies probably give very similar reactions too. What we see affects us in very 
similar ways. The horror film is the spectator's symptom, and I can enjoy horror only as long as films manage to develop this (perverse) enjoyment in me. Technology interacts with the human (like in Cronenberg's Videodrome), producing new enjoyments and frenzies of the flesh. But is it something really so new? What about Pygmalion and the dozens of stories from Antiquity in which people fall in love or make love to beautiful statues? It seems that the human subject is always already a post-human subject: open to art, to technology, to film, to new perversions that (re)organise one's relationship to enjoyment. [Figs. 8-9.]

What are my chances of making sense of my own obscene symptomatic supplement? How could the subject conceptually describe one's relation to that thing that wounds, punctuates, and organises one's enjoyment, that serves as a perverse supplement of subjectivity? How could I have control over the visual field when the point is precisely that I get lost in it? How could I have the distance, the perspective, the mastery needed for an analysis? I can analyse film only as long as I manage to break its spell, get free from its subjugating power: I stop the film, make tea, freeze the frame, turn down the volume, step back from the screen, move one frame forward and two back. This is the only way I can regain enough mastery to think, analyse and write, to put the image into perspective, to return the experience from the traumatic enjoyment of punctum to the pleasurable control of studium. And even when I manage to do that, when I make sense of the film like psychoanalysts make sense of symptoms and horror film protagonists make sense of monsters, the results are never more than nice cover stories: the traumatic core, the Real thing, just like Myers's body at the end of Halloween, ultimately always escapes.

\section{References}

Belting, Hans. 1994. Likeness and Presence. A History of the Image before the Era of Art. Chicago: University of Chicago Press.

Barthes, Roland. 1981. Camera Lucida. Reflections on Photography. New York: Hill and Wang.

Brousse, Marie-Hélène. 2007. Hysteria and Sinthome. In The Later Lacan. An Introduction, eds. Veronique Voruz and Bogdan Wolf, 83-94. Albany: State University of New York Press.

Clover, Carol J. 2002. Her Body, Himself: Gender in the Slasher Film. In Horror. The Film Reader ed. Mark Jancovich, 77-90. London and New York: Routledge. 
McGowan, Todd. 2007. The Real Gaze. Film Theory After Lacan. New York: State University of New York Press.

Rockoff, Adam. 2002. Going to Pieces. The Rise and Fall of the Slasher Film, 1978-1986. Jefferson: McFarland.

Shaviro, Steven. 1993. The Cinematic Body. Minneapolis, London: University of Minnesota Press.

Silverman, Kaja. 1996. The Threshold of the Visible World. London: Routledge.

Worland, Rick. 2007. Halloween (1978). The Shape of the Slasher Film. In The Horror Film. An Introduction, ed. Rick Worland, 227-242. Oxford: Blackwell.

\section{List of Figures}

Figures 1-2.
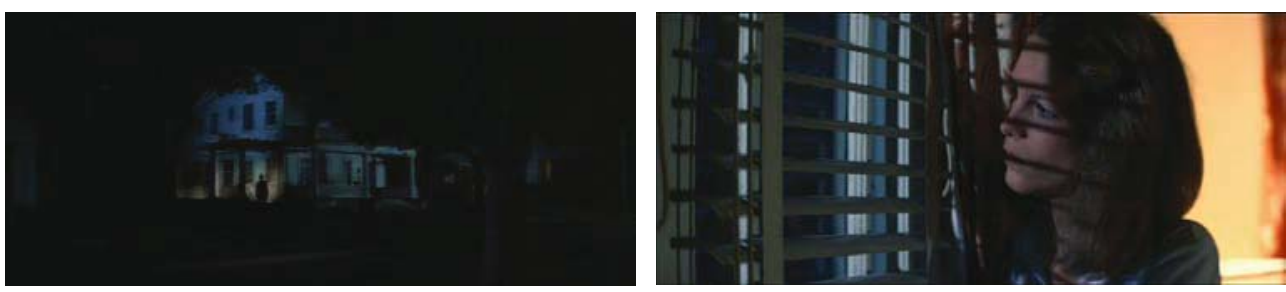

Figures 3-4.
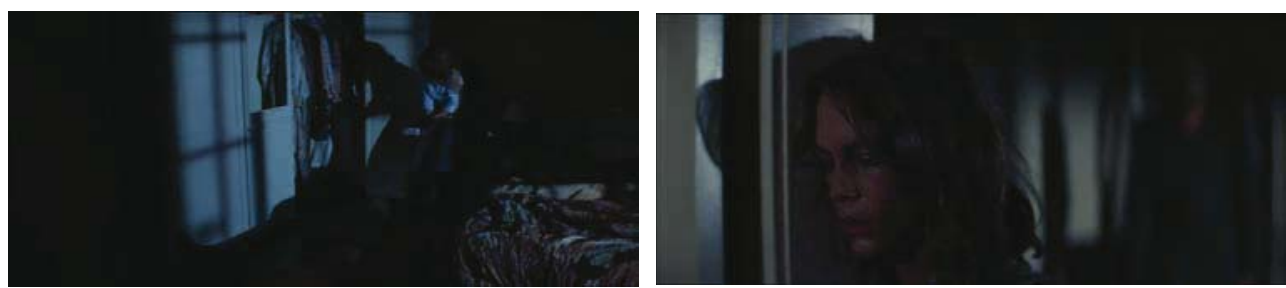
Figure 5.

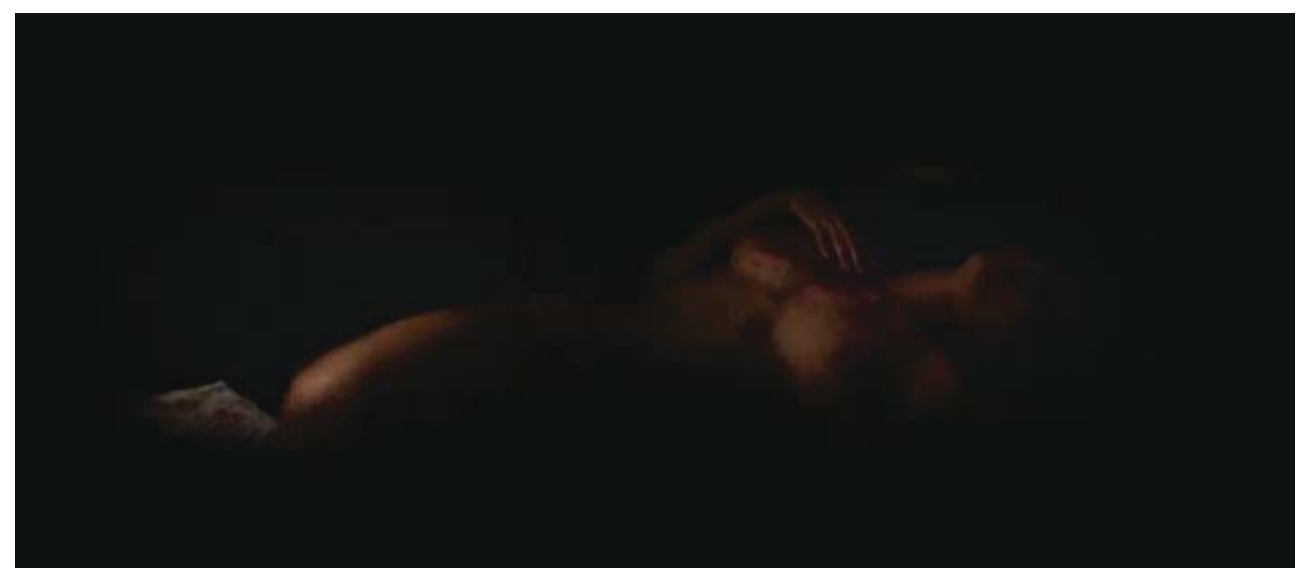

Figures 6-7.
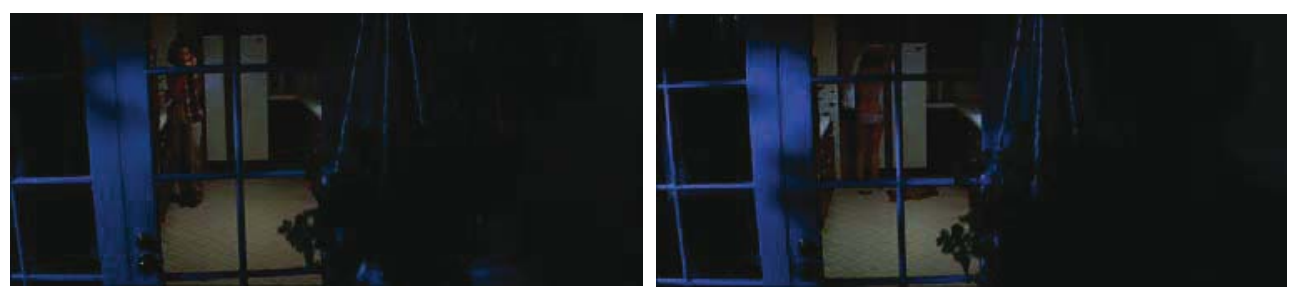

Figures 8-9.
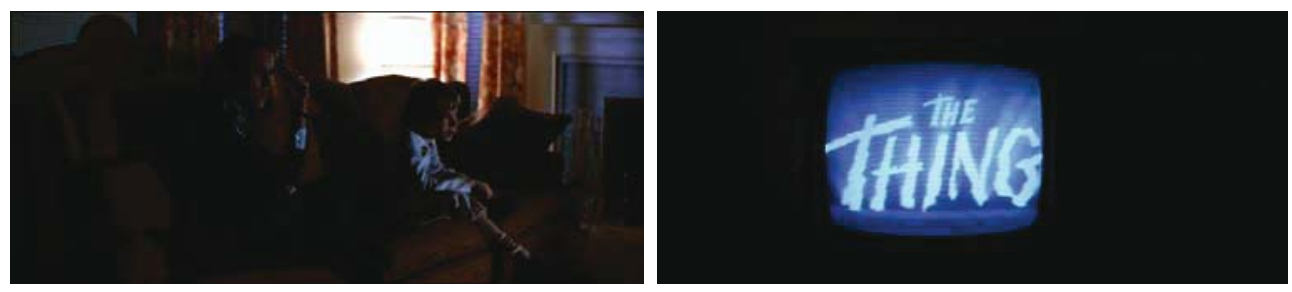